\title{
Long-course neoadjuvant chemoradiotherapy with versus without a concomitant boost in locally advanced rectal cancer: a randomized, multicenter, phase II trial (FDRT-002)
}

Jingwen Wang ${ }^{1,2 \dagger}$, Yun Guan ${ }^{3,4 \dagger}$, Weilie Gu ${ }^{1,5}$, Senxiang Yan ${ }^{6}$, Juying Zhou ${ }^{7}$, Dan Huang ${ }^{1,8}$, Tong Tong ${ }^{1,9}$, Chao Li ${ }^{10,11}$, Sanjun Cai ${ }^{1,5}$, Zhen Zhang ${ }^{1,2^{*}}$ and Ji Zhu ${ }^{1,2^{*}}$ (i)

\begin{abstract}
Background: This study was designed to explore whether an intensified chemoradiotherapy (CRT) led to a better clinical outcome in locally advanced rectal cancer.

Methods: Patients with stage II/III rectal cancer were randomly allocated to receive either pelvic intensitymodulated radiation therapy (IMRT) of $50 \mathrm{~Gy} / 25 \mathrm{Fx}$ concurrently with capecitabine and oxaliplatin (Arm A), or pelvic radiation of $50 \mathrm{~Gy} / 25 \mathrm{Fx}$ with a concomitant boost of $5 \mathrm{~Gy}$ to the primary lesion, followed by a cycle of XELOX 2 weeks after the end of CRT (Arm B). All patients were planned to receive a definitive operation 8 weeks after the completion of CRT and a total of six perioperative chemotherapy cycles of capecitabine and oxaliplatin regardless of pathological result. Pathological complete response (ypCR) was the primary endpoint.

Results: From February 2010 to December 2011, 120 patients from three centers were enrolled in this study. Ninetyfive percent patients completed a full-dose chemoradiotherapy as planning. Then 53 and 57 patients received a radical surgery, and 8 and 14 cases were confirmed as ypCR in two groups $(P=0.157)$. The other 10 patients failed to receive a definitive resection because of unresectable disease. Similar toxicities were observed between two groups and more incision healing delay were found in Arm B (3 vs.13, $P=0.011)$. No statistical differences were observed in local-regional control $(P=0.856)$, disease-free survival $(P=0.349)$ and overall survival $(P=0.553)$. Mesorectal fascia (MRF) involvement was an independent prognostic factor for survival in multivariate analysis.
\end{abstract}

Conclusions: A concomitant boost to oxalipatin-combined preoperative chemoradiotherapy demonstrated a slightly higher $p C R$ rate but delayed incision healing after surgery. The impact of MRF involvement on survival merits further investigations.

Trial registration: NCT01064999 (ClinicalTrials.gov).

Keywords: Rectal cancer, Neoadjuvant chemoradiotherapy, Intensity-modulated radiation therapy

\footnotetext{
* Correspondence: zhenzhang6@gmail.com; leoon.zhu@gmail.com

${ }^{\dagger}$ Jingwen Wang and Yun Guan contributed equally to this work.

'Department of Oncology, Shanghai Medical College, Fudan University,

Shanghai 200032, China

Full list of author information is available at the end of the article
}

(c) The Author(s). 2019 Open Access This article is distributed under the terms of the Creative Commons Attribution 4.0 International License (http://creativecommons.org/licenses/by/4.0/), which permits unrestricted use, distribution, and reproduction in any medium, provided you give appropriate credit to the original author(s) and the source, provide a link to the Creative Commons license, and indicate if changes were made. The Creative Commons Public Domain Dedication waiver (http://creativecommons.org/publicdomain/zero/1.0/) applies to the data made available in this article, unless otherwise stated. 


\section{Introduction}

With report of results from a series of large randomized clinical trials comparing neoadjuvant pelvic radiotherapy (RT) alone versus RT plus concurrent 5-fluorouracil (5FU), the standard modality for stage II/III rectal cancer has shifted to preoperative chemoradiotherapy (CRT), followed by total mesorectal excision (TME) and postoperative chemotherapy, which leads to preservation of normal tissue, improvement of tumor regression and excellent local control [1].

The German CAO/ARO/AIO-94 study is the milestone of preoperative CRT [2]. Patients who received preoperative RT in the study had superior local control and reduced toxicity compared with patients in the postoperative group. Subsequently, the EORTC 22921 trial [3] and FFCD9203 trial [4] suggested 5-FU-based CRT resulted in a lower local recurrence rate compared with long-course RT alone, in spite of similar long-term survival. Furthermore, in EORTC 22921 trial, the ypT0-2 group had a significant better OS and DFS than the ypT3-4 group [5]. Similar results were also observed in MDACC's retrospective study, where tumor regression could be converted to a better long-term prognosis [6]. Moreover, in a pooled analysis [7], it was reported that patients with $\mathrm{pCR}$ after CRT have better long-term outcome than do those without pCR (5-year crude DFS: $83.3 \%$ vs $65.6 \%)$. Therefore, in some views, tumor downstaging, especially pCR, was regarded as a goal in neoadjuvant treatment of locally advanced rectal cancer, which motivated the combination of systemic chemotherapy and advanced RT technique in this approaches.

In our center, previous phase II studies reported that oxaliplatin plus 5-FU-based CRT showed good tumor responses and tolerable toxicities [8-10]. Higher radiation dose was reported to contribute to tumor downstaging in literatures [11-13]. Therefore, we designed this randomized trial to explore whether a combined regimen of oxaliplatin-added chemoradiotherapy and a concomitant boost to the primary tumor would further lead to a better clinical outcome.

\section{Patients and methods}

\section{Patient eligibility}

The main inclusion criteria of this study were as follows: (1) newly diagnosed rectal adenocarcinoma; (2) aged between 18 and 75 years old; (3) tumor located within 12 $\mathrm{cm}$ from anal verge; (4) clinically staged T3-4 and/or $\mathrm{N}+$; (5) no evidence of distant metastases; (6) had Karnofsky Performance Status score of 60 or more; and (7) had adequate hematologic, renal and hepatic function.

Patients were excluded if they had history of malignant tumor but not including cured skin cancer or cervical cancer in situ, had inflammatory bowel disease, ischemic heart disease, peripheral neuropathy, or psychological disorders. Informed consent must be obtained from every patient before randomization. The procedure of random assignment was performed centrally at the Fudan University Shanghai Cancer Center.

\section{Treatment schedule}

The IMRT technique and tumor volumes definition has been described in our previous trial [9]. For Arm A, the planning dose to the PTV2 (pelvis) were $50 \mathrm{~Gy}$ in 25 fractions, five times per week (Monday through Friday) over 5 weeks. For Arm B, the planning doses to the PTV1 (primary tumor) and PTV2 were 55 Gy and 50 Gy in 25 fractions. Electronic portal imaging device (EPID) films were used to verify the isocenter and positioning of each patient for the anterior and lateral gantry positions.

Capecitabine and oxaliplatin were given in combination with pelvic radiotherapy. The concurrent chemotherapy regimen was same in both Arms. Capecitabine of $625 \mathrm{mg} / \mathrm{m}^{2}$ was given twice daily from Monday to Friday, and oxaliplatin was administered at a fix dose of 50 $\mathrm{mg} / \mathrm{m}^{2} /$ week throughout the entire course of CRT. Two weeks after the end of CRT, one additional cycle of XELOX (capecitabine $1000 \mathrm{mg} / \mathrm{m}^{2}$ twice daily on day $1-$ 14 and oxaliplatin $130 \mathrm{mg} / \mathrm{m}^{2}$ on day 1) was scheduled for patients in Arm B (Fig. 1).

After the completion of CRT, patients were planned to undergo TME 8 weeks later, while the operation type, such as abdominal-perineal resection (APR) or low anterior resection (LAR), and whether to perform a temporary colostomy, were left to the surgeon to decide. All patients were recommended to receive a total of six cycles of XELOX in perioperative period, regardless of their pathological features.

\section{Treatment evaluation and follow-up}

Baseline evaluation included a comprehensive medical history collection, digital examination, colonoscopy and biopsy, computed tomography (CT) scanning of chest and abdomen, and magnetic resonance imaging (MRI) of pelvis. Endorectal ultrasound (EUS) and positron emission tomography (PET) were not routinely recommended.

Pathologic examination of surgical specimens was performed in accordance with the American Joint Committee on Cancer (AJCC, Version 7) [14]. If less than 12 lymph nodes were found during standard examination for resected lymph nodes, two pathologists needed to double check to verify the number of lymph nodes. The tumor regression grade (TRG) after chemoradiotherapy was recorded according to the AJCC TRG system. TRG 0: Complete tumor response-no viable cancer cells; TRG 1: Moderate response-single or small groups of tumor cells; TRG 2: Minimal responseresidual cancer outgrown by fibrosis; TRG 3: Poor 


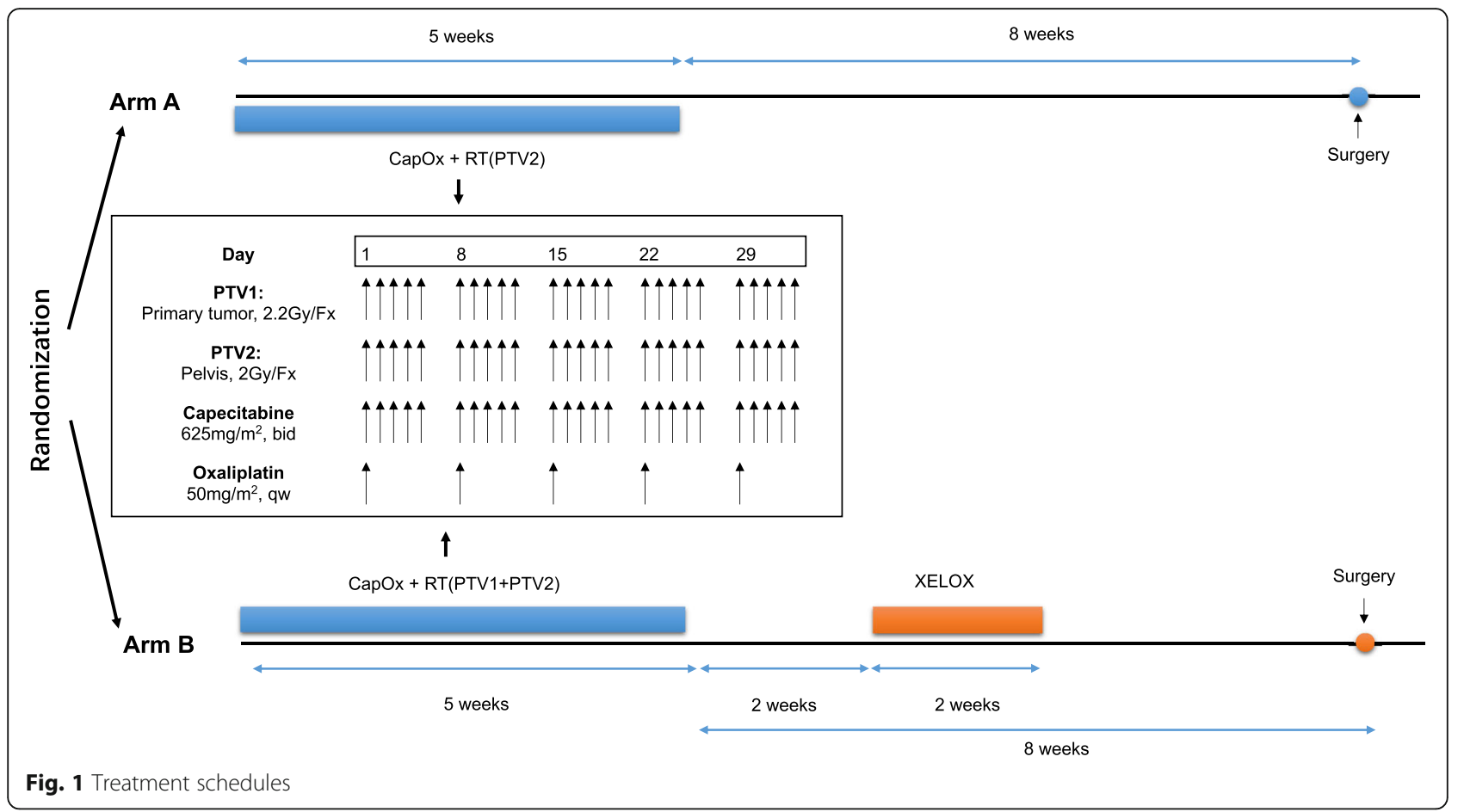

response-minimal or no tumor cells killed. PCR was defined as the absence of viable tumor cells in the resection specimens including the primary tumor and lymph nodes (ypTON0), and near-pCR was defined as ypT0N1a or TRG1 in our study. Those with a margin of circumferential rectal margin $(\mathrm{CRM})<1 \mathrm{~mm}$ were marked in positive status [15].

Acute toxicities were defined as toxicities occurred during the entire course of CRT and were evaluated weekly according to the National Cancer Institute Common Toxicity Criteria (CTCAE 4.0). Follow-up was scheduled every 3 months during the first 2 years after surgery, and then every 6 months over the next 3 years. After 5 years, the frequency of follow-up was extended to once each year.

\section{Endpoints and statistics}

An intention-to-treat (ITT) dataset including all eligible patients were used in the analysis procedure. The hypothesis was to increase the ypCR rate from $10 \%$ in the Arm A to $25 \%$ in the Arm B. A total of 120 patients were required to detect such a difference, with $\alpha=0.20$ (two tailed) and power $=0.80$. Secondary endpoints were listed as follows: toxicities, sphincter preservation rate, local failure (LF), disease-free survival (DFS) and overall survival (OS).

All features were listed by mean and standard deviations for normal distributional data, by median and interquartile range (IQR) for non-normal distributional data, and by frequency for categorical variables.
Comparisons between two groups were performed using $\chi^{2}$ tests for categorical variable. Survival curves were estimated using the Kaplan-Meier method and compared with Log-rank test. Cox proportional hazards regression was used for univariate and multivariate modeling and for examining the prognostic significance of the variables identified in the model. $P$ values of less than 0.05 were taken to indicate statistically significant differences.

\section{Results}

\section{Baseline characteristics}

From February 2010 to December 2011, 120 eligible patients in three centers (Fudan University Shanghai Cancer Center, Shanghai, China; The First Affiliated Hospital, College of Medicine, Zhejiang University, Hangzhou, China; The First Affiliated Hospital of Suzhou University, Suzhou, China) were randomly assigned in the trial, and the final analysis was performed in ITT set including all 120 cases (Fig. 2).

Patient characteristics were presented in Table 1. Eighty-four were male and 36 were female, and the median age was 56 (range 22-75). More cases were diagnosed with cT3, cN+, negative mesorectal fascia (MRF) and with the distance from anal verge less than $5 \mathrm{~cm}$. No statistical differences were observed between two groups in the baseline characteristics (Table 1).

\section{Compliance and toxicities}

Full-dose radiotherapy was given in $98.3 \%$ patients in both groups. One case in Arm B received single drug 


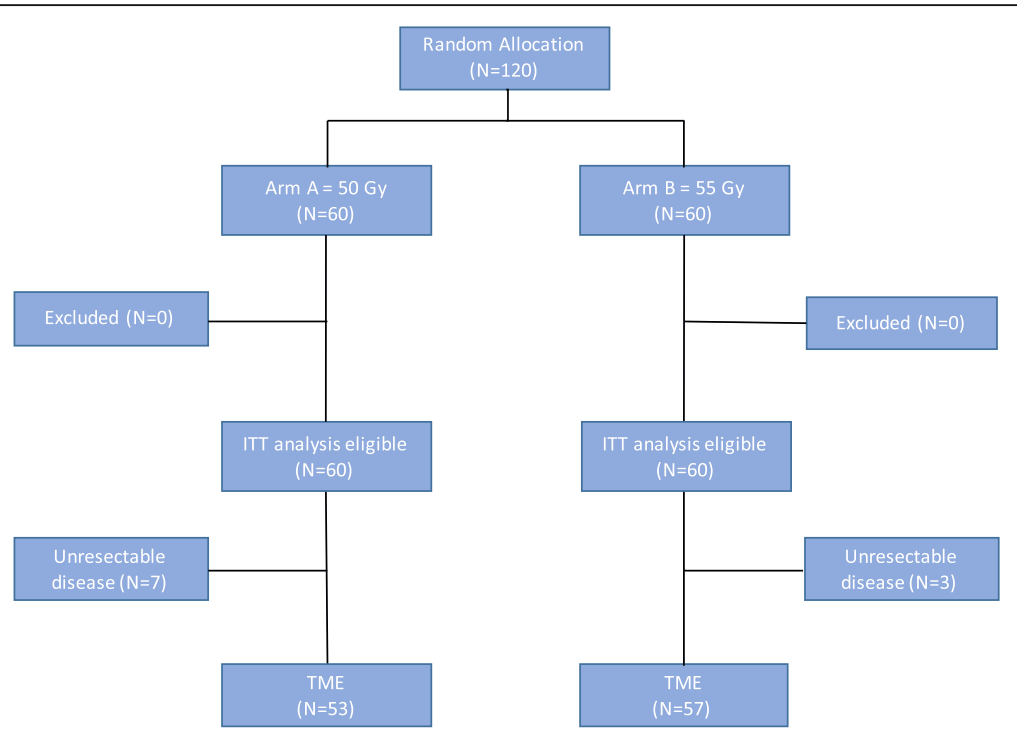

Fig. 2 CONSORT for FDRT-002 trial. Arm A, 5 weeks of treatment with radiotherapy 50 Gy $/ 25$ fractions with concurrent capecitabine 625 mg $/ \mathrm{m}^{2}$ twice daily 5 days per week and oxaliplatin $50 \mathrm{mg} / \mathrm{m}^{2}$ once weekly; Arm B, 5 weeks of treatment with radiotherapy 55 Gy/25 fractions with concurrent capecitabine $625 \mathrm{mg} / \mathrm{m}^{2}$ twice daily 5 days per week and oxaliplatin $50 \mathrm{mg} / \mathrm{m}^{2}$ once weekly, followed by a cycle of XELOX. ITT, intention to treat; TME, total mesorectal excision

Table 1 Baseline characteristics of patients $(N=120)$

\begin{tabular}{|c|c|c|c|c|c|c|c|}
\hline & \multicolumn{2}{|c|}{ Arm A } & \multicolumn{2}{|c|}{ Arm B } & \multicolumn{2}{|c|}{ Total } & \multirow{2}{*}{$\begin{array}{l}P \\
\text { value }\end{array}$} \\
\hline & No. & $\%$ & No. & $\%$ & No. & $\%$ & \\
\hline \multicolumn{8}{|l|}{ Gender } \\
\hline Male & 42 & $70.00 \%$ & 42 & $70.00 \%$ & 84 & $70.00 \%$ & \\
\hline Female & 18 & $30.00 \%$ & 18 & $30.00 \%$ & 36 & $30.00 \%$ & 1.000 \\
\hline \multicolumn{8}{|l|}{ Age, years } \\
\hline$<=55$ & 27 & $45.00 \%$ & 27 & $45.00 \%$ & 54 & $45.00 \%$ & \\
\hline$>55$ & 33 & $55.00 \%$ & 33 & $55.00 \%$ & 66 & $55.00 \%$ & 1.000 \\
\hline \multicolumn{8}{|c|}{ Clinical T stage } \\
\hline T3 & 40 & $66.70 \%$ & 45 & $75.00 \%$ & 85 & $70.80 \%$ & \\
\hline T4 & 20 & $33.30 \%$ & 15 & $25.00 \%$ & 35 & $29.20 \%$ & 0.315 \\
\hline \multicolumn{8}{|c|}{ Clinical N stage } \\
\hline NO & 14 & $23.30 \%$ & 14 & $23.30 \%$ & 28 & $23.30 \%$ & \\
\hline $\mathrm{N}+$ & 46 & $76.70 \%$ & 46 & $76.70 \%$ & 92 & $76.70 \%$ & 1.000 \\
\hline \multicolumn{8}{|l|}{ MRF } \\
\hline- & 36 & $60.00 \%$ & 38 & $63.30 \%$ & 74 & $61.70 \%$ & \\
\hline+ & 24 & $40.00 \%$ & 22 & $36.70 \%$ & 46 & $38.30 \%$ & 0.707 \\
\hline \multicolumn{8}{|c|}{ Location from anal verge, $\mathrm{cm}$} \\
\hline$<=5 \mathrm{~cm}$ & 40 & $66.70 \%$ & 40 & $66.70 \%$ & 80 & $66.70 \%$ & \\
\hline$>5 \mathrm{~cm}$ & 20 & $33.30 \%$ & 20 & $33.30 \%$ & 40 & $33.30 \%$ & 1.000 \\
\hline \multicolumn{8}{|c|}{ Length of the tumor } \\
\hline$<=5 \mathrm{~cm}$ & 31 & $51.70 \%$ & 22 & $36.70 \%$ & 53 & $44.20 \%$ & \\
\hline$>5 \mathrm{~cm}$ & 29 & $48.30 \%$ & 38 & $63.30 \%$ & 67 & $55.80 \%$ & 0.098 \\
\hline Total & 60 & $50 \%$ & 60 & $50 \%$ & 120 & $100 \%$ & \\
\hline
\end{tabular}

Arm A, 5 weeks of treatment with radiotherapy $50 \mathrm{~Gy} / 25$ fractions with concurrent capecitabine $625 \mathrm{mg} / \mathrm{m}^{2}$ twice daily 5 days per week and oxaliplatin $50 \mathrm{mg} / \mathrm{m}^{2}$ once weekly; Arm B, 5 weeks of treatment with radiotherapy $55 \mathrm{~Gy} / 25$ fractions with concurrent capecitabine $625 \mathrm{mg} / \mathrm{m}^{2}$ twice daily 5 days per week and oxaliplatin $50 \mathrm{mg} / \mathrm{m}^{2}$ once weekly, followed by a cycle of XELOX Abbreviations: MRF Mesorectal fascia during the whole course of CRT for the reason that he refused intravenous chemotherapy. Almost all patients completed five cycles of weekly oxaliplatin, except that one and four patients terminated oxaliplatin in the second and fourth cycles, respectively. No further chemotherapy dose modification was recorded.

The overall acute grade 3-4 toxicities were 18.3 and $25.0 \%$ in the two groups, Arm A and Arm B, respectively. Diarrhea, radiation dermatitis and nausea were the three most common toxicities in both groups, though a slightly higher number of above cases were found in Arm B without significant difference (Table 2).

\section{Surgical procedures and pathological outcome}

Radical surgery was performed in 53 (88.3\%) patients in arm A and 57 (95.0\%) in arm B after a median interval between CRT and surgery of 51 and 58 days, respectively. The other ten patients failed to undergo a surgery due to unresectable diseases. Anterior resection procedure was performed in 13 and 22 patients (24.5 and $38.6 \%$ of the patients who underwent surgery in arms A and arm B), respectively (Table 3). Arm B demonstrated a slightly better ypCR, ypT and ypN stage. PCR were found in 22 cases, 8 in Arm A and 14 in Arm B. There were 45.3 and $31.6 \%$ patients demonstrating positive lymph nodes in two groups, respectively. The rate of anastomotic fistula and low anterior resection syndrome were equally low in both arms, but more delayed incision healing were observed in Arm B (Table 4).

In additional analysis for tumor response, good response was defined as pCR plus near-pCR, the others 
Table 2 Acute toxicity according to CTCAE 4.0, on all patients receiving treatment

\begin{tabular}{|c|c|c|c|c|c|c|c|c|c|}
\hline \multirow[t]{3}{*}{ Adverse Event } & \multicolumn{4}{|c|}{ Grade 1-2 } & \multicolumn{4}{|c|}{ Grade 3-4 } & \multirow{3}{*}{$\begin{array}{l}P \\
\text { value* }\end{array}$} \\
\hline & \multicolumn{2}{|c|}{$\operatorname{Arm~A~}(N=60)$} & \multicolumn{2}{|c|}{$\operatorname{Arm~B}(N=60)$} & \multicolumn{2}{|c|}{$\operatorname{Arm~A}(N=60)$} & \multicolumn{2}{|c|}{$\operatorname{Arm~B}(N=60)$} & \\
\hline & No. & $\%$ & No. & $\%$ & No. & $\%$ & No. & $\%$ & \\
\hline Diarrhea & 21 & $35.0 \%$ & 16 & $26.7 \%$ & 4 & $6.7 \%$ & 6 & $10.0 \%$ & 0.721 \\
\hline Nausea & 35 & $58.3 \%$ & 31 & $51.7 \%$ & 2 & $3.3 \%$ & 3 & $5.0 \%$ & 0.683 \\
\hline Vomiting & 5 & $8.3 \%$ & 7 & $11.7 \%$ & 2 & $3.3 \%$ & 2 & $3.3 \%$ & 0.608 \\
\hline Anorexia & 13 & $21.7 \%$ & 18 & $30.0 \%$ & 0 & $0.0 \%$ & 1 & $1.7 \%$ & 0.203 \\
\hline Radiodermatitis & 27 & $45.0 \%$ & 22 & $36.7 \%$ & 8 & $13.3 \%$ & 10 & $16.7 \%$ & 0.807 \\
\hline Anemia & 37 & $61.7 \%$ & 34 & $56.7 \%$ & 0 & $0.0 \%$ & 0 & $0.0 \%$ & 0.581 \\
\hline leukopenia & 16 & $26.7 \%$ & 21 & $35.0 \%$ & 2 & $3.3 \%$ & 2 & $3.3 \%$ & 0.360 \\
\hline Neutropenia & 15 & $25.0 \%$ & 20 & $33.3 \%$ & 2 & $3.3 \%$ & 3 & $5.0 \%$ & 0.247 \\
\hline Thrombopenia & 27 & $45.0 \%$ & 25 & $41.7 \%$ & 2 & $3.3 \%$ & 1 & $1.7 \%$ & 0.543 \\
\hline Overall & 40 & $66.7 \%$ & 43 & $71.7 \%$ & 11 & $18.3 \%$ & 15 & $25.0 \%$ & 0.077 \\
\hline
\end{tabular}

Arm A, 5 weeks of treatment with radiotherapy $50 \mathrm{~Gy} / 25$ fractions with concurrent capecitabine $625 \mathrm{mg} / \mathrm{m}^{2}$ twice daily 5 days per week and oxaliplatin $50 \mathrm{mg} / \mathrm{m}^{2}$ once weekly; Arm B, 5 weeks of treatment with radiotherapy $55 \mathrm{~Gy} / 25$ fractions with concurrent capecitabine $625 \mathrm{mg} / \mathrm{m}^{2}$ twice daily 5 days per week and oxaliplatin $50 \mathrm{mg} / \mathrm{m}^{2}$ once weekly, followed by a cycle of XELOX

Abbreviations: MRF Mesorectal fascia

*All $P$ values are comparison of grade 3 and 4 adverse events between the two arms

were marked as poor response, including those who could not receive surgery for unresectable lesion. A higher good response rate was observed in Arm B (30\% vs. $55 \%, P=0.006$ ) (Table 5). Two patients in Arm A received additional postoperative radiotherapy of $10-15$ Gy because of a positive margin.

\section{Long-term prognosis}

A total of 49 patients in Arm A and 51 in Arm B received adjuvant CT. The most frequent regimen was XELOX, with median of three cycles.

With a median follow-up of 42 months (range 3.280.7 months), ten patients were confirmed with local recurrence and 26 patients were diagnosed with distant metastases. A total of 20 patients died, 17 of cancerrelated disease, 3 of other reasons. There were no significant differences in 3-year local-regional failure (10.9\% vs. 9.4\%, $P=0.856)$, 3 -year DFS ( $56.0 \%$ vs. $68.8 \%, P=0.349)$ and 3 -year OS $(75.3 \%$ vs. $88.5 \%, P=0.553)$ between two groups (Fig. 3).

\section{Univariate and multivariate analysis of OS, DFS and LC}

All potential prognostic factors, including demographic and clinical features were evaluated using Kaplan-Meier and Cox model (Table 6). Positive MRF was associated with poorer local control, DFS and OS; ypN and tumor response were correlated with DFS and OS; pCR was in favor of longer DFS. In the multivariate Cox model, ypT, ypN and pCR were excluded because they exhibited a strong correlation with tumor response. MRF was the only independent prognostic factor for local control, DFS and OS simultaneously. Tumor response was also an independent risk factor for DFS (Table 7).

\section{Discussion}

This phase II randomized trial was designed to compare two different dose-intensified regimens in neoadjuvant therapy. With the preset alpha of 0.20 , the primary endpoint reached an expected higher $\mathrm{pCR}$ rate $(13.3 \%$ vs.

Table 3 Pathologic characteristics of the operative specimen from patients $\left(N=110^{a}\right)$

\begin{tabular}{|c|c|c|c|c|c|c|c|}
\hline & \multicolumn{2}{|c|}{ Arm A } & \multicolumn{2}{|c|}{ Arm B } & \multicolumn{2}{|c|}{ Total } & \multirow{2}{*}{$\begin{array}{l}P \\
\text { value }\end{array}$} \\
\hline & No. & $\%$ & No. & $\%$ & No. & $\%$ & \\
\hline \multicolumn{8}{|l|}{ Type of surgery } \\
\hline Miles & 36 & $67.90 \%$ & 32 & $56.10 \%$ & 68 & $61.80 \%$ & \\
\hline Anterior resection & 13 & $24.50 \%$ & 22 & $38.60 \%$ & 35 & $31.80 \%$ & \\
\hline Hartmann & 4 & $7.50 \%$ & 3 & $5.30 \%$ & 7 & $6.40 \%$ & 0.279 \\
\hline \multicolumn{8}{|l|}{ ypT stage } \\
\hline урт0 & 10 & $18.90 \%$ & 16 & $28.10 \%$ & 26 & $23.60 \%$ & \\
\hline ypT1-2 & 16 & $30.20 \%$ & 24 & $42.10 \%$ & 40 & $36.40 \%$ & \\
\hline ypT3-4 & 27 & $50.90 \%$ & 17 & $29.80 \%$ & 44 & $40.00 \%$ & 0.077 \\
\hline \multicolumn{8}{|l|}{ ypN stage } \\
\hline NO & 29 & $54.70 \%$ & 39 & $68.40 \%$ & 68 & $61.80 \%$ & \\
\hline $\mathrm{N}+$ & 24 & $45.30 \%$ & 18 & $31.60 \%$ & 42 & $38.20 \%$ & 0.139 \\
\hline \multicolumn{8}{|l|}{$\mathrm{pCR}$} \\
\hline $\mathrm{pCR}$ & 8 & $15.10 \%$ & 14 & $24.60 \%$ & 22 & $20.00 \%$ & \\
\hline non-pCR & 45 & $84.90 \%$ & 43 & $75.40 \%$ & 88 & $80.00 \%$ & 0.215 \\
\hline Total & 53 & & 57 & & 110 & & \\
\hline
\end{tabular}

Arm A, 5 weeks of treatment with radiotherapy $50 \mathrm{~Gy} / 25$ fractions with concurrent capecitabine $625 \mathrm{mg} / \mathrm{m}^{2}$ twice daily 5 days per week and oxaliplatin $50 \mathrm{mg} / \mathrm{m}^{2}$ once weekly; Arm B, 5 weeks of treatment with radiotherapy $55 \mathrm{~Gy} / 25$ fractions with concurrent capecitabine $625 \mathrm{mg} / \mathrm{m}^{2}$ twice daily 5 days per week and oxaliplatin $50 \mathrm{mg} / \mathrm{m}^{2}$ once weekly, followed by a cycle of XELOX

Abbreviations: $p C R$ Pathological complete response; ${ }^{\text {aP }}$ Patients who did not undergo surgery excluded 
Table 4 Postoperative surgical complications $\left(N=110^{a}\right)$

\begin{tabular}{llll}
\hline Complications & Arm A $(N=53)$ & Arm B $(N=57)$ & $P$ value \\
\hline Total & 4 & 14 & 0.016 \\
Local fistula & 1 & 0 & 0.482 \\
LARS $^{\text {a }}$ & 0 & 1 & 0.491 \\
Delayed incision healing & 3 & 13 & 0.011
\end{tabular}

Arm A, 5 weeks of treatment with radiotherapy $50 \mathrm{~Gy} / 25$ fractions with concurrent capecitabine $625 \mathrm{mg} / \mathrm{m}^{2}$ twice daily 5 days per week and oxaliplatin $50 \mathrm{mg} / \mathrm{m}^{2}$ once weekly; Arm B, 5 weeks of treatment with radiotherapy $55 \mathrm{~Gy} / 25$ fractions with concurrent capecitabine $625 \mathrm{mg} / \mathrm{m}^{2}$ twice daily 5 days per week and oxaliplatin $50 \mathrm{mg} / \mathrm{m}^{2}$ once weekly, followed by a cycle of XELOX

Abbreviations: LARS Low anterior resection syndrome; ${ }^{\text {aP }}$ atients who did not undergo surgery excluded

$23.3 \%, P=0.157)$. Furthermore, the intensified dose regimen was associated with better tumor response but more delayed incision healing after surgery in the experimental arm (Arm B). Therefore, our results suggested that the enhanced dose regimen with a concomitant
Table $\mathbf{5}$ pCR rate and patient response $\left(N=120^{\mathrm{a}}\right)$

\begin{tabular}{|c|c|c|c|c|c|c|c|}
\hline & \multicolumn{2}{|c|}{ Arm A } & \multicolumn{2}{|c|}{ Arm B } & \multicolumn{2}{|c|}{ Total } & \multirow{2}{*}{$\begin{array}{l}P \\
\text { value }\end{array}$} \\
\hline & No. & $\%$ & No. & $\%$ & No. & $\%$ & \\
\hline \multicolumn{8}{|l|}{$\mathrm{pCR}$} \\
\hline$p C R$ & 8 & $13.3 \%$ & 14 & $23.3 \%$ & 22 & $18.3 \%$ & \\
\hline non-pCR & 52 & $86.7 \%$ & 46 & $76.7 \%$ & 98 & $81.7 \%$ & .157 \\
\hline \multicolumn{8}{|l|}{ Response } \\
\hline Good & 18 & $30.0 \%$ & 33 & $55.0 \%$ & 51 & $42.5 \%$ & \\
\hline Poor & 42 & $70.0 \%$ & 27 & $45.0 \%$ & 69 & $57.5 \%$ & .006 \\
\hline
\end{tabular}

Good response: $\mathrm{pCR}$ plus near pCR; Poor response: others

Abbreviations: $p C R$ Pathological complete response

apatients who did not undergo surgery included

boost to the primary tumor in oxaliplatin-added neoadjuvant chemoradiotherapy warrant more attentions.

In the design of our study, the hypothesis was that the intensified treatment would lead to a better tumor regression, as well as a longer survival. Therefore,

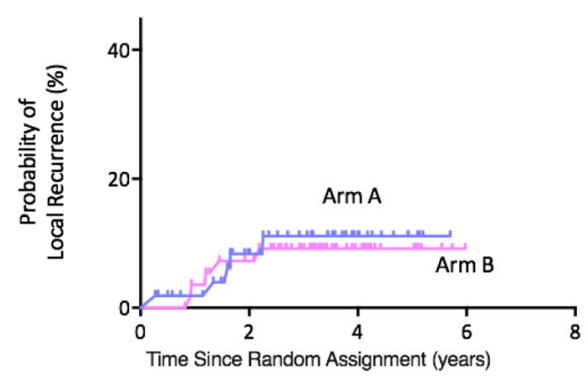

$\begin{array}{lcc}\text { A } & \begin{array}{c}\text { No. of } \\ \text { Patients }\end{array} & \begin{array}{c}\text { 3-year Local Recurrence } \\ \text { Rates }\end{array} \\ \text { Arm A } & 60 & 10.9 \% \\ \text { Arm B } & 60 & 9.4 \% \\ & & \\ & & P=0.856\end{array}$

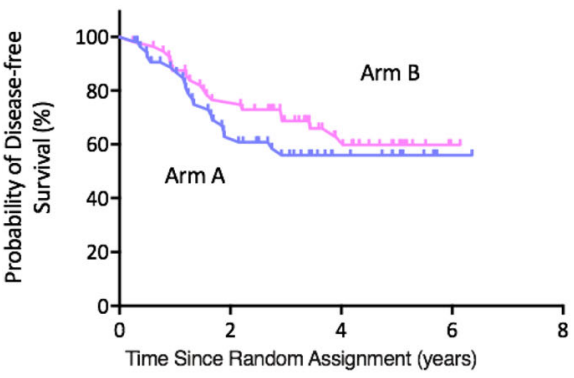

B $\begin{gathered}\text { No. of } \\ \text { Patients }\end{gathered} \quad \begin{gathered}\text { 3-year Disease-free } \\ \text { Survival Rates }\end{gathered}$

$\begin{array}{lll}\text { Arm A } & 60 & 56.0 \%\end{array}$

Arm B $60 \quad 68.8 \%$

$P=0.349$

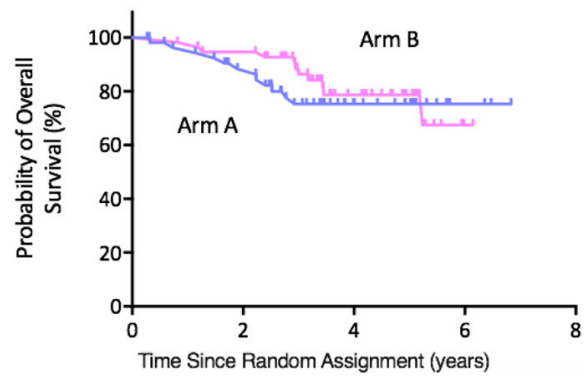
C No. of 3-year Overall Survival Patients Rates
$\begin{array}{lll}\text { Arm A } & 60 & 75.3 \%\end{array}$
$\begin{array}{lll}\text { Arm B } & 60 & 88.5 \%\end{array}$

$P=0.553$

Fig. 3 Long-term survival. a Cumulative incidence of local recurrences; $\mathbf{b}$ Disease-free survival and $\mathbf{c}$ Overall survival in the intention-to-treat population 
Table 6 Results of the univariate analysis of prognostic factors on overall survival, disease-free survival, local control

\begin{tabular}{|c|c|c|c|c|c|c|c|c|c|}
\hline \multirow[t]{2}{*}{ Factor } & \multicolumn{3}{|c|}{ Overall Survival } & \multicolumn{3}{|c|}{ Disease-free Survival } & \multicolumn{3}{|c|}{ Local Control } \\
\hline & $\mathrm{HR}$ & $95 \% \mathrm{Cl}$ & $P$ & $\mathrm{HR}$ & $95 \% \mathrm{Cl}$ & $P$ & $\mathrm{HR}$ & $95 \% \mathrm{Cl}$ & $P$ \\
\hline \multicolumn{10}{|l|}{ Gender } \\
\hline male / female & 0.849 & $0.334-2.160$ & 0.731 & 1.280 & $0.674-2.434$ & 0.451 & 0.588 & $0.125-2.771$ & 0.502 \\
\hline \multicolumn{10}{|l|}{ Age } \\
\hline$>55 /<=55$ & 0.737 & $0.325-1.672$ & 0.465 & 0.872 & $0.476-1.599$ & 0.658 & 2.002 & $0.518-7.742$ & 0.315 \\
\hline \multicolumn{10}{|l|}{ Treatment } \\
\hline high-dose / low-dose & N/A & N/A & N/A & N/A & N/A & N/A & 0.892 & $0.258-3.082$ & 0.856 \\
\hline \multicolumn{10}{|l|}{ CT stage } \\
\hline cT4 / cT3 & 1.319 & $0.542-3.209$ & 0.542 & 1.166 & $0.596-2.278$ & 0.654 & 0.318 & $0.040-2.511$ & 0.277 \\
\hline \multicolumn{10}{|l|}{ cN stage } \\
\hline $\mathrm{cN}+/ \mathrm{cNO}$ & 1.051 & $0.390-2.835$ & 0.921 & 1.036 & $0.496-2.166$ & 0.925 & 2.678 & $0.339-21.146$ & 0.350 \\
\hline \multicolumn{10}{|l|}{ MRF } \\
\hline MRF+ / MRF- & 2.971 & $1.297-6.802$ & 0.010 & 2.485 & $1.351-4.572$ & 0.003 & 4.802 & $1.240-18.590$ & 0.023 \\
\hline \multicolumn{10}{|l|}{ Location } \\
\hline$>5 \mathrm{~cm} / \leq 5 \mathrm{~cm}$ & 1.191 & $0.515-2.753$ & 0.683 & 0.888 & $0.462-1.709$ & 0.723 & 0.484 & $0.103-2.280$ & 0.359 \\
\hline \multicolumn{10}{|l|}{ Length } \\
\hline$>5 \mathrm{~cm} / \leq 5 \mathrm{~cm}$ & 1.563 & $0.662-3.693$ & 0.308 & 1.219 & $0.658-2.260$ & 0.528 & 2.059 & $0.532-7.965$ & 0.296 \\
\hline \multicolumn{10}{|l|}{ урт } \\
\hline урТ1-2/ypT0 & 1.047 & $0.294-3.734$ & 0.944 & 1.672 & $0.641-4.363$ & 0.294 & 1.797 & $0.187-17.278$ & 0.612 \\
\hline урT3-4 / урт0 & 1.238 & $0.372-4.114$ & 0.728 & 2.116 & $0.838-5.339$ & 0.113 & 3.620 & $0.436-30.080$ & 0.234 \\
\hline \multicolumn{10}{|l|}{ ypN } \\
\hline ypN+ / ypNo & 3.518 & $1.346-9.191$ & 0.010 & 2.234 & $1.178-4.234$ & 0.014 & 0.776 & $0.201-3.004$ & 0.714 \\
\hline \multicolumn{10}{|l|}{$\mathrm{pCR}$} \\
\hline non-pCR / pCR & 2.728 & $0.639-11.646$ & 0.175 & 2.656 & $0.946-7.459$ & 0.064 & 2.058 & $0.261-16.257$ & 0.494 \\
\hline \multicolumn{10}{|l|}{ Response } \\
\hline Poor / Good & 2.574 & $1.013-6.544$ & 0.047 & 2.228 & $1.156-4.297$ & 0.017 & 1.224 & $0.345-4.339$ & 0.755 \\
\hline
\end{tabular}

Good response: $\mathrm{pCR}$ plus near pCR; Poor response: others

Abbreviations: HR Hazard ratio, $p C R$ Pathological complete response, MRF Mesorectal fascia

enhanced treatment dose intensity was regarded as an effective method, including both radiotherapy and chemotherapy dose. Plenty of early phase II trials indicated that it was beneficial to add oxaliplatin to standard FU-based CRT [16], and several continuous small sample size studies in our center also showed similar results $[8,9]$. Therefore, based on literature review at that time, oxaliplatin was administered in both two arms in this trial. Additionally, our previous study reported that $23.7 \%$ patients were evaluated as $\mathrm{pCR}$, who received
IMRT to the pelvis of $50 \mathrm{~Gy}$ and a concomitant boost of 5 Gy to the primary tumor, in combination with oxaliplatin and capecitabine, followed by a cycle of XELOX before surgery [8]. Therefore, a concomitant boost to the primary tumor was regarded as an efficient supplementary to the approach and this regimen was recommended as the experimental arm in this trial.

Noticed the rate of pCR was $23.3 \%$ in the experimental arm compared with $13.3 \%$ in the controlled arm in the present study, it may be resulted from both

Table 7 Results of the multivariate analysis of prognostic factors on overall survival, disease-free survival, local control

\begin{tabular}{lllll}
\hline Factor & Factor & $P$ value & $95 \% \mathrm{Cl}$ & $\mathrm{HR}$ \\
\hline Overall Survival & MRF+/MRF- & 0.023 & $4.802-1.240$ & 18.590 \\
Disease-free Survival & MRF+/MRF- & 0.011 & $2.231-1.203$ & 4.136 \\
& Poor response/Good response & 0.047 & $1.959-1.007$ & 3.808 \\
Local Control & MRF+/MRF- & 0.010 & $2.971-1.297$ & 6.802 \\
\hline
\end{tabular}


chemotherapy and radiation dose escalation. Even though in the next six phase III trials, the mainstream view considered no significant benefit was brought by additional oxaliplatin [17-24], we still hold some different opinions as follows: the completion proportion of oxaliplatin during CRT ranges from 41 to $94.5 \%$ in these trials, which may be a leading cause of inconsistent results. It is worthy more attention that two trials having an enhanced $\mathrm{pCR}$ rate demonstrated a high completion proportion of oxaliplatin of $85 \%$ or more (CAO/ARO/AIO-04 and FORWARC trial) [19, 21]. Therefore, a pooled analysis including all above trials is expected to identify the subgroup population who can really benefit from additional oxaliplatin.

Furthermore, with the development of RT technique, such as IMRT and brachytherapy, higher preoperative pelvic irradiation dose was delivered in some studies. Radiation dose was regarded as a significant factor in the degree of tumor downstaging as reported by Mohiuddin et al. [11], whose study suggested that the rate of pCR was significantly correlated with RT dose, as patients treated to a dose of less than 50 Gy had a downstaging rate of $67 \%$ and a pCR rate of $3 \%$, compared with a downstaging rate of $89 \%$ and a pCR rate of $45 \%$ at doses of more than $55 \mathrm{~Gy}(P=0.05)$. What's more, in The Radiation Oncology Group (RTOG) 0012 phase II trial [12], patients were randomly assigned to either hyperfractionated pelvic RT plus continuous infusion 5-FU or standard pelvic RT plus continuous infusion 5-FU and irinotecan, and both arms achieved very high $\mathrm{pCR}$ rates of $26 \%$ in each arm. So, the intensified RT dose plays a role in preoperative treatment of LARC.

In the uni- and multi-variate analysis of our study, we found that MRF status played as independent prognostic factors for long-term prognosis. As reported in the experience of MERCURY trial [25], MRI-defined involvement of CRM is an independent prognostic factor for 5-year overall survival (mrCRM+ vs mrCRM-: $62.2 \%$ vs $42.2 \%$ ), for DFS (67.2\% vs $47.3 \%$ ) and for local recurrence with a hazard ratio of $3.5(P<0.05)$. In our study, the results was similar. Nevertheless, since the sample size was small, we couldn't perform subgroup analysis to verify the conclusion.

However, this study had some limitations. Firstly, the control arm was not the current standard of care for locally advanced rectal cancer. As we stated previously, when we designed and conducted this study, oxaliplatin was still in high expectation in the neoadjuvant CRT phase. Secondly, it was indeed difficult to clarify which is the main reason for a better tumor response and more severe toxicities since radiation dose and consolidation chemotherapy were enhanced simultaneously in the experimental group. Thirdly, we didn't notice any longterm benefit in the group with higher $\mathrm{pCR}$ rate. As it was common in most phase II trials in neoadjuvant treatment of LARC, the improvement of pCR rate was difficult to convert to a longer survival. Last but not the least, this study was originally designed as a two-stage trial with a total sample size of 240 . But because of the disappointed results of several phase III trials about additional oxaliplatin in neoadjuvant CRT, we terminated this study after the completion of the first phase.

\section{Conclusion}

A concomitant boost to oxalipatin-combined preoperative chemoradiotherapy demonstrated contribution to tumor regression with acceptable acute toxicity, but led to delayed incision healing after surgery. More data are needed to assess the impact of dose-intensified radiotherapy on long-term survival. The impact of MRF involvement on survival merits further investigation. Considered the experimental regimen was not compared to the standard of care, the conclusion should be interpreted cautiously.

\section{Abbreviations \\ AJCC: American Joint Committee on Cancer; APR: Abdominal-perineal resection; CRM: Circumferential rectal margin; CRT: Chemoradiotherapy; CT: Computed tomography; CTCAE: National Cancer Institute Common Toxicity Criteria; DFS: Disease-free survival; EPID: Electronic portal imaging device; IMRT: Intensity-modulated radiation therapy; ITT: Intention-to-treat; LAR: Low anterior resection; LARC: Locally advanced rectal cancers; LR: Local control rate; MRI: Magnetic resonance imaging; OS: Overall survival; PET: Positron emission tomography; PTV: Planning target volume; TME: Total mesorectal excision; UICC: International Union against Cancer}

\section{Acknowledgements}

We would like to thank all the patients who participated in the present trial. We are also grateful to all the colleagues of Department of Colorectal Surgery in Fudan University Shanghai Cancer Center who have been involved with performing the treatment for the present study.

\section{Authors' contributions}

JZ and ZZ designed the trial, JW and YG drafted and revised the manuscript, and all authors read and approved the final manuscript.

\section{Funding}

This study was funded by Natural Science Foundation of Shanghai (19ZR1410600).

\section{Availability of data and materials}

The datasets used and/or analyzed during the current study are available from the corresponding author on reasonable request.

\section{Ethics approval and consent to participate}

This study was undertaken in accordance with the ethical standards of the World Medical Association Declaration of Helsinki. The trial protocol was approved by the Institutional Review Board on Medical Ethics at Fudan University Shanghai Cancer Center, and was registered at ClinicalTrials.gov (NCT 01064999). All study participants provided written informed consent prior to treatment.

Consent for publication

Not applicable.

Competing interests

The authors declare that they have no competing interests. 


\section{Author details}

'Department of Oncology, Shanghai Medical College, Fudan University, Shanghai 200032, China. ${ }^{2}$ Department of Radiation Oncology, Fudan University Shanghai Cancer Center, Shanghai 200032, China. ${ }^{3}$ Cyberknife Center, Department of Neurosurgery, Huashan Hospital, Fudan University, Shanghai 200040, China. ${ }^{4}$ Neursurgical Institute of Fudan University, Shanghai 200040, China. ${ }^{5}$ Department of Colorectal Surgery, Fudan University Shanghai Cancer Center, Shanghai 200032, China. ${ }^{6}$ Department of Radiation Oncology, The First Affiliated Hospital, College of Medicine, Zhejiang University, Hangzhou, China. 'Department of Radiation Oncology, 1st Affiliated Hospital of Suzhou (Soochow) University, Suzhou, China. ${ }^{8}$ Department of Pathology, Fudan University Shanghai Cancer Center, Shanghai 200032, China. ${ }^{9}$ Department of Radiology, Fudan University Shanghai Cancer Center, Shanghai 200032, China. ${ }^{10}$ Department of Radiation oncology, Huashan Hospital, Fudan University, Shanghai 200040, China.

${ }^{11}$ Department of Cyberknife Center, Huashan Hospital, Fudan University, Shanghai 200040, China.

Received: 3 September 2019 Accepted: 14 November 2019

Published online: 29 November 2019

\section{References}

1. Benson AB, Venook AP, Al-Hawary MM, Cederquist L, Chen YJ, Ciombor KK, et al. Rectal cancer, version 2.2018, NCCN clinical practice guidelines in oncology. J Natl Compr Cancer Netw. 2018;16:874-901.

2. Sauer R, Becker H, Hohenberger W, Rodel C, Wittekind C, Fietkau R, et al. Preoperative versus postoperative chemoradiotherapy for rectal cancer. N Engl J Med. 2004;351:1731-40.

3. Bosset JF, Calais G, Mineur L, Maingon P, Radosevic-Jelic L, Daban A, et al. Enhanced tumorocidal effect of chemotherapy with preoperative radiotherapy for rectal cancer: preliminary results--EORTC 22921. J Clin Oncol. 2005;23:5620-7.

4. Gerard JP, Conroy T, Bonnetain F, Bouche O, Chapet O, Closon-Dejardin MT, et al. Preoperative radiotherapy with or without concurrent fluorouracil and leucovorin in T3-4 rectal cancers: results of FFCD 9203. J Clin Oncol. 2006;24:4620-5.

5. Bosset JF, Calais G, Mineur L, Maingon P, Stojanovic-Rundic S, Bensadoun RJ, et al. Fluorouracil-based adjuvant chemotherapy after preoperative chemoradiotherapy in rectal cancer: long-term results of the EORTC 22921 randomised study. Lancet Oncol. 2014;15:184-90.

6. Park IJ, You YN, Agarwal A, Skibber JM, Rodriguez-Bigas MA, Eng C, et al. Neoadjuvant treatment response as an early response indicator for patients with rectal cancer. J Clin Oncol. 2012;30:1770-6.

7. Maas M, Nelemans PJ, Valentini V, Das P, Rodel C, Kuo LJ, et al. Long-term outcome in patients with a pathological complete response after chemoradiation for rectal cancer: a pooled analysis of individual patient data. Lancet Oncol. 2010;11:835-44.

8. Zhu J, Liu F, Gu W, Lian P, Sheng W, Xu J, et al. Concomitant boost IMRT-based neoadjuvant chemoradiotherapy for clinical stage II/III rectal adenocarcinoma: results of a phase II study. Radiat Oncol. 2014;9:70.

9. Zhu J, Gu W, Lian P, Sheng W, Cai G, Shi D, et al. A phase II trial of neoadjuvant IMRT-based chemoradiotherapy followed by one cycle of capecitabine for stage II/III rectal adenocarcinoma. Radiat Oncol. 2013;8:130,

10. Zhu J, Lian P, Liu F, Xu Y, Xu J, Guan Z, et al. Phase II trial of first-line chemoradiotherapy with intensity-modulated radiation therapy followed by chemotherapy for synchronous unresectable distant metastases rectal adenocarcinoma. Radiat Oncol. 2013;8:10.

11. Mohiuddin M, Regine WF, John WJ, Hagihara PF, McGrath PC, Kenady DE, et al. Preoperative chemoradiation in fixed distal rectal cancer: dose time factors for pathological complete response. Int J Radiat Oncol Biol Phys. 2000;46:883-8.

12. Mohiuddin M, Winter K, Mitchell E, Hanna N, Yuen A, Nichols C, et al. Randomized phase II study of neoadjuvant combined-modality chemoradiation for distal rectal cancer: radiation therapy oncology group trial 0012. J Clin Oncol. 2006;24:650-5.

13. Appelt AL, Ploen J, Harling H, Jensen FS, Jensen LH, Jorgensen JC, et al. High-dose chemoradiotherapy and watchful waiting for distal rectal cancer: a prospective observational study. Lancet Oncol. 2015;16:919-27.

14. Edge SB, Compton CC. The American Joint Committee on Cancer: the 7th edition of the AJCC cancer staging manual and the future of TNM. Ann Surg Oncol. 2010;17:1471-4.
15. Quirke P, Durdey P, Dixon MF, Williams NS. Local recurrence of rectal adenocarcinoma due to inadequate surgical resection. Histopathological study of lateral tumour spread and surgical excision. Lancet. 1986;2:996-9.

16. Hartley A, Ho KF, McConkey C, Geh Jl. Pathological complete response following pre-operative chemoradiotherapy in rectal cancer: analysis of phase II/III trials. Br J Radiol. 2005;78:934-8.

17. Gerard JP, Azria D, Gourgou-Bourgade S, Martel-Lafay I, Hennequin C, Etienne PL, et al. Clinical outcome of the ACCORD 12/0405 PRODIGE 2 randomized trial in rectal cancer. J Clin Oncol. 2012;30:4558-65.

18. Aschele C, Cionini L, Lonardi S, Pinto C, Cordio S, Rosati G, et al. Primary tumor response to preoperative chemoradiation with or without Oxaliplatin in locally advanced rectal cancer: pathologic results of the STAR-01 randomized phase III trial. J Clin Oncol. 2011;29:2773-80.

19. Deng Y, Chi P, Lan P, Wang L, Chen W, Cui L, et al. Modified FOLFOX6 with or without radiation versus fluorouracil and Leucovorin with radiation in Neoadjuvant treatment of locally advanced rectal cancer: initial results of the Chinese FOWARC multicenter, open-label, randomized three-arm phase III trial. J Clin Oncol. 2016;34:3300-7.

20. Gerard JP, Azria D, Gourgou-Bourgade S, Martel-Laffay I, Hennequin C, Etienne PL, et al. Comparison of two neoadjuvant chemoradiotherapy regimens for locally advanced rectal cancer: results of the phase III trial ACCORD 12/0405-Prodige 2. J Clin Oncol. 2010;28:1638-44.

21. Rödel C, Liersch T, Becker H, Fietkau R, Hohenberger W, Hothorn T, et al. Preoperative chemoradiotherapy and postoperative chemotherapy with fluorouracil and oxaliplatin versus fluorouracil alone in locally advanced rectal cancer: initial results of the German CAO/ARO/AlO-04 randomised phase 3 trial. Lancet Oncol. 2012;13:679-87.

22. O'Connell MJ, Colangelo LH, Beart RW, Petrelli NJ, Allegra CJ, Sharif S, et al. Capecitabine and Oxaliplatin in the preoperative multimodality treatment of rectal cancer: surgical end points from national surgical adjuvant breast and bowel project trial $R^{-04}$. J Clin Oncol. 2014;32:1927-34.

23. Hans-Joachim Schmoll KH, Timothy Jay Price BN, Ralf Hofheinz JD, et al. Preoperative chemoradiotherapy and postoperative chemotherapy with capecitabine and oxaliplatin versus capecitabine alone in locally advanced rectal cancer: first results of the PETACC-6 randomized phase III trial. J Clin Oncol. 2013;31(suppl):3531.

24. Rödel C, Graeven U, Fietkau R, Hohenberger W, Hothorn T, Arnold D, et al. Oxaliplatin added to fluorouracil-based preoperative chemoradiotherapy and postoperative chemotherapy of locally advanced rectal cancer (the German CAO/ARO/AIO-04 study): final results of the multicentre, open-label, randomised, phase 3 trial. Lancet Oncol. 2015;16:979-89.

25. Patel UB, Taylor F, Blomqvist L, George C, Evans H, Tekkis P, et al. Magnetic resonance imaging-detected tumor response for locally advanced rectal cancer predicts survival outcomes: MERCURY experience. J Clin Oncol. 2011; 29:3753-60

\section{Publisher's Note}

Springer Nature remains neutral with regard to jurisdictional claims in published maps and institutional affiliations.

Ready to submit your research? Choose BMC and benefit from:

- fast, convenient online submission

- thorough peer review by experienced researchers in your field

- rapid publication on acceptance

- support for research data, including large and complex data types

- gold Open Access which fosters wider collaboration and increased citations

- maximum visibility for your research: over $100 \mathrm{M}$ website views per year

At BMC, research is always in progress.

Learn more biomedcentral.com/submissions 